\title{
Use of complementary and alternative medicine by patients with lysosomal storage diseases
}

\author{
Manisha Balwani, $M S, M D^{l}$, Laura Fuerstman, $M A^{l}$, Robert J. Desnick, $M D, P h D^{I}$, Brian Buckley, $B A^{l}$, \\ and Margaret M. McGovern, MD, PhD ${ }^{1,2}$
}

\begin{abstract}
Purpose: To evaluate the extent of complementary and alternative medicine use and perceived effectiveness in patients with lysosomal storage diseases. Methods: A 26-item survey was distributed to 495 patients with type 1 Gaucher, Fabry, and type B Niemann-Pick diseases who were seen at the Lysosomal Storage Disease Program at the Mount Sinai School of Medicine. Survey responses were entered into an access database and analyzed using descriptive statistics. Results: Surveys were completed by 167 respondents with an overall response rate of $34 \%$. Complementary and alternative medicines were used by $45 \%$ of patients with type 1 Gaucher disease, $41 \%$ of patients with Fabry disease, and $47 \%$ of patients with type B Niemann-Pick for symptoms related to their disease. Complementary and alternative medicines were used most frequently by adult females $(55 \%)$, in patients who reported having one or more invasive procedures due to their disease, patients who use one or more conventional medical therapies, or those with depression and/or anxiety. Overall perceived effectiveness of complementary and alternative medicine supplements was low; however, complementary and alternative medicine therapies were perceived as effective. Conclusion: Complementary and alternative medicines are commonly used among patients with lysosomal storage diseases. Assessment of the effectiveness of these approaches in the lysosomal storage diseases is needed, and physicians should be aware of complementary and alternative medicine therapies used by patients to evaluate safety and possible drug interactions. Genet Med 2009:11(10): 722-727.
\end{abstract}

Key Words: complementary medicine, alternative medicine, lysosomal storage diseases, effectiveness, safety

Complementary and alternative medicines (CAMs) are de- fined by the National Center for Complementary and Alternative Medicine as "a group of diverse medical and health care systems, practices, and products that are not presently considered to be part of conventional medicine."1 These include the use of herbal and other supplements, massage, acupuncture, and sets of theories and practices such as homeopathy. In general, interest in CAMs among patients is high, and adults report using CAMs for a wide variety of indications including chronic pain, anxiety, fatigue, and musculoskeletal problems. ${ }^{1-3}$ Patients with various chronic illnesses are known to use CAMs because they believe conventional medical treatments will not

From the ${ }^{1}$ Department of Genetics and Genomic Sciences, Mount Sinai School of Medicine, New York City; and ${ }^{2}$ Department of Pediatrics, Stony Brook University School of Medicine, Stony Brook, New York.

Manisha Balwani, MS, MD, Department of Genetics and Genomic Sciences, One Gustave L. Levy Place, Box 1497, New York City, NY 10029. E-mail: manisha.balwani@mssm.edu.

The authors declare no conflict of interest.

Submitted for publication April 9, 2009

Accepted for publication June 5, 2009.

Published online ahead of print September 10, 2009.

DOI: 10.1097/GIM.0b013e3181b182c3 help them or that a combination of traditional and alternative treatments will help. ${ }^{2}$ The types and frequencies of use of CAMs by patients with lysosomal storage diseases (LSDs) have not been investigated. The CAMs used in specific LSDs may be of concern because some disorders have significant hepatic, cardiac, and/or renal involvement. For example, several CAM supplements have been associated with drug interactions including liver ${ }^{4,5}$ and renal ${ }^{6,7}$ toxicities.

Here, we investigated by written questionnaire the use of CAMs among patients affected with type 1 Gaucher, Fabry, and type B Niemann-Pick diseases. These diseases are characterized by manifestations involving the bone marrow, bone, liver, lung, and spleen (type 1 Gaucher and type B Niemann-Pick diseases) and the vasculature, heart, and kidney (Fabry disease). Symptoms include bone pain and fatigue (type 1 Gaucher disease), neuropathic pain, fatigue, gastrointestinal, cardiac and vascular complaints (Fabry disease), and shortness of breath, abdominal pain, and fatigue (type B Niemann-Pick disease). ${ }^{8-11}$ Currently, enzyme replacement therapies (ERT) are available for Gaucher and Fabry diseases, and an ERT is in clinical trials for type B Niemann-Pick disease. ${ }^{12}$ Because most of the patients in this survey had type 1 Gaucher or Fabry disease, their use of CAMs, in addition to the biweekly ERT, was of interest. These studies revealed significant use of supplements, alternative therapies, and alternative medicine practitioners for symptoms related to these LSDs.

\section{METHODS}

A 26-item questionnaire of closed- and open-ended questions was developed to obtain information from patients about their use and the perceived effectiveness of CAMs. Items included questions about: symptoms experienced by the patient, the use of conventional medications, and about specific CAM supplements including glucosamine, chondroitin, cayenne, cat's claw, $S$-adenosyl-L-methionine, ginseng, ostivone, boswella, oligomeric proanthocyanidins, ginger, gingko, echinacea, Chinese herbal medicine, omega-3 fatty acids, flaxseed, cod liver oil, antioxidants, methylsulfonylmethane, noni juice, kava tea, yucca, and megavitamin therapy. In addition, the questionnaire inquired about the use of various CAM treatments (meditation, yoga, biofeedback, herbal medicine, homeopathy, reflexology, massage, macrobiotics, magnetic therapy, acupuncture, acupressure, water therapy, chiropractic, relaxation therapy, spiritual/energy healing, aromatherapy, and therapeutic touch) and CAM providers (chiropractors, acupuncturists, acupressurists, Chinese herbal medicine practioners, homeopaths, and naturopaths). Patients were asked how they learned about CAMs, whether or not they had ever discussed CAMs with their physician, and relevant demographic information. Subjects also were asked to report their perceptions about the efficacy of CAMs using a Likert scale of $0-5$ with 0 being not effective and 5 being very effective.

Questionnaires were distributed to patients with type 1 Gaucher, Fabry, and type B Niemann-Pick diseases who were 
evaluated at the General Clinical Research Center of the Mount Sinai School of Medicine between November 2006 and August 2007. Surveys were also mailed to patients previously seen on the General Clinical Research Center and known to the investigators. Parents completed the questionnaires for children who were younger than 18 years. All study procedures were approved by the Institutional Review Board of the Mount Sinai School of Medicine.

The survey data were entered into a Microsoft Access database. Descriptive statistics were calculated for response patterns related to demographic and disease type, use of specific types of CAMs, and opinions on CAM efficacy. Pearson's $\chi^{2}$ test was used to determine significance of CAM use within each disease population.

\section{RESULTS}

\section{Demographics of participants}

Of the 495 patients, 237, 210, and 48 had type 1 Gaucher, Fabry, and type B Niemann-Pick diseases, respectively. The overall response rate was $34 \%(n=167)$. Table 1 shows the overall and disease-specific demographics of the participants. Of the 167 respondents, $17 \%$ were children ( $<18$ years; $n=$ 28), $83 \%$ were adults ( $>18$ years; $n=139), 60 \%$ had type 1 Gaucher, 29\% had Fabry disease, and 11\% were patients with type B Niemann-Pick disease. Among the pediatric patients, $36 \%$ were female, $43 \%$ had type 1 Gaucher, 14\% had Fabry, and $43 \%$ had type B Niemann-Pick disease. Among the adult respondents, $55 \%$ were women, and $60 \%$ had type 1 Gaucher, $29 \%$ had Fabry, and 11\% had type B Niemann-Pick disease. More than $90 \%$ of the respondents were whites, and $71 \%$ had a college degree or higher. Seventy-six percent (107/140) of the patients with type 1 Gaucher and Fabry diseases were on ERT.

\section{Use of CAMs}

Among the adult patients with type 1 Gaucher and Fabry diseases, 45\% (37/83) and 41\% (17/41) used CAMs, respectively (Table 1 ), whereas only $8 \%$ of children with type 1 Gaucher disease (1/12) and 50\% children with Fabry $(2 / 4)$ reported CAM use. Of patients with type B Niemann-Pick disease, $47 \%(7 / 15)$ of adults and $33 \%(4 / 12)$ of children used CAMs. CAMs were used more frequently among adult females $(55 \%, 43 / 78)$ than males $(30 \%, 18 / 61, P=0.003)$. Overall, CAMs were used most in patients with LSD older than 65 years $(65 \%, 15 / 23)$ followed by patients aged $25-34$ years $(55 \%$, $11 / 20), 55-64$ years $(48 \%, 14 / 29), 45-54$ years $(45 \%, 14 / 31)$, and $35-44$ years $(27 \%, 6 / 22)$. Only one patient in the $18-24-$ year-old group reported the use of CAMs; this patient had type B Niemann-Pick disease. Overall, the average age of patients using CAMs was 53.7 years for type 1 Gaucher disease, 47.7 years for Fabry disease, and 31.8 years for type B NiemannPick disease. Of interest, CAM use was higher $(56 \% ; P=$ $0.015)$, among patients with LSD who reported having one or more disease-related invasive procedures (e.g., coronary artery bypass surgery, hemodialysis, kidney and liver transplants, splenectomy, hip replacement, and tracheostomy), having used one or more conventional therapies $(68 \%, P<0.001)$, and having symptoms of depression and/or anxiety $(66 \% ; P<0.001)$.

\section{Use and perceived effectiveness of CAM supplements}

Of the adult patients with type 1 Gaucher disease, $34 \%$ (28/83) used CAM supplements. The most commonly used supplements were glucosamine $(20 \%, 17 / 83)$ and chondroitin $(14 \%, 12 / 83)$, including some patients $(13 \%, 11 / 83)$ who used both glucosamine and chondroitin. In addition, patients with type 1 Gaucher disease also reported the use of antioxidants $(14 \%, 12 / 83)$ and omega-3 fatty acids $(12 \%, 10 / 83)$. The CAM supplements, Echinacea and methylsulfonylmethane, used by $10 \%$ of the patients with Gaucher disease were taken for immunity and pain, respectively (Table 2). Similarly, 29\% (12/41) of adult patients with Fabry disease took supplements, including antioxidants $(12 \%, 5 / 41)$, omega-3 fatty acids $(12 \%, 5 / 41)$, flaxseed $(12 \%, 5 / 41)$, gingko $(10 \%, 4 / 41)$, and megavitamin therapy $(10 \%, 4 / 41)$. Among adult patients with type B Niemann-Pick disease, omega-3 fatty acids were the most commonly used supplement $(40 \%, 6 / 15)$.

Of note, the two most commonly used CAM supplements reported by patients with Gaucher disease (i.e., glucosamine and antioxidants) had low-mean Likert effectiveness scores (1.8 and 1.6, respectively). Patients with Fabry and type B Niemann-Pick diseases who commonly used omega-3 fatty acids and antioxidants also rated them low on the Likert scale. CAM use among children was limited to one child (flaxseed) with type B Niemann-Pick disease (Table 3).

\section{Use and perceived effectiveness of CAM treatments}

As shown in Table 4, therapeutic massage was the most commonly used treatment modality by patients with type 1 Gaucher (12\%), Fabry (12\%), and type B Niemann-Pick (27\%) diseases and was rated on the Likert scale as above average on perceived effectiveness by all the three groups (Likert score $=$ $3.4, n=14$ ). Chiropractic manipulation (Likert score $=3.3$, $n=10$ ) and meditation (Likert score $=3.8, n=12$ ) were also rated above average. There was little use of CAM treatments among the LSD children (Table 3).

\section{Use of CAM practitioners}

Of note, $17 \%$ of adult patients with Gaucher disease $(n=$ $14), 12 \%$ of adult patients with Fabry disease $(n=5)$, and $47 \%$ $(n=7)$ of adult patients with type B Niemann-Pick disease had sought advice from a CAM practitioner, with the most common providers being acupuncturists for patients with Gaucher disease $(n=6)$, and chiropractors for patients with Fabry $(n=3)$ and Niemann-Pick $(n=5)$ diseases. Only two children with type B Niemann-Pick disease used alternative providers, a homeopathic and a naturopathic provider.

Most patients $(44 \%, n=27)$ who used various CAM therapies self-initiated the treatment. Of those who had sought out a CAM provider, $58 \%$ indicated that the visits to the alternative medicine provider were covered by health insurance. Other sources of information about CAMs were from their medical doctors, self-help books, and family and friends. Notably, 28\% of those who were using supplements never discussed their CAM use with their physician, although most patients, $86 \%$ of those using CAMs and $75 \%$ of those not using CAMs, indicated that they would like to discuss CAM therapies with their physicians.

\section{DISCUSSION}

The use of CAMs has been studied in many chronic medical conditions. ${ }^{2,13-15}$ However, to date, the prevalence of CAM use in any of the LSDs has not been investigated. The results of this study suggest that CAM use is prevalent among patients with type 1 Gaucher and Fabry diseases, two disorders specifically treated by ERT. Of the 124 adult type 1 Gaucher disease and Fabry disease respondents, 44\% used CAMs (45\% Gaucher and $41 \%$ Fabry) for symptoms related to their disease, including bone pain and fatigue for type I Gaucher disease, and for 
Table 1 Demographics of all respondents

\begin{tabular}{|c|c|c|c|}
\hline & Type 1 Gaucher & Fabry & Type B Niemann-Pick \\
\hline Patients sent questionnaire & 237 & 210 & 48 \\
\hline Patients responding, $n(\%)$ & $95(40)$ & $45(21)$ & $27(56)$ \\
\hline Male & $47(49)$ & $20(44)$ & $12(44)$ \\
\hline Female & $48(51)$ & $25(56)$ & $15(56)$ \\
\hline Age range (years) & $1-78$ & $13-68$ & $1-70$ \\
\hline Children $<18$ years, $n(\%)$ & $12(13)$ & $4(9)$ & $12(44)$ \\
\hline $18-24$ years, $n(\%)$ & $4(4)$ & $5(11)$ & $5(19)$ \\
\hline $25-34$ years, $n(\%)$ & $15(16)$ & $3(7)$ & $2(7)$ \\
\hline $35-44$ years, $n(\%)$ & $10(11)$ & $9(20)$ & $3(11)$ \\
\hline $45-54$ years, $n(\%)$ & $20(21)$ & $8(18)$ & $3(11)$ \\
\hline $55-64$ years, $n(\%)$ & $15(16)$ & $13(29)$ & $1(4)$ \\
\hline 65 years and older, $n(\%)$ & $19(20)$ & $3(7)$ & $1(4)$ \\
\hline Mean (years) & 45 & 44 & 25 \\
\hline Median (years) & 48 & 48 & 19 \\
\hline Race & $N=94$ & $N=44$ & $N=27$ \\
\hline White, $n(\%)$ & $89(95)$ & $38(86)$ & $25(93)$ \\
\hline African American/black, $n(\%)$ & $1(1)$ & $4(9)$ & 0 \\
\hline Hispanic, $n(\%)$ & $2(2)$ & $1(2)$ & 0 \\
\hline Asian, $n(\%)$ & $2(2)$ & $1(2)$ & 0 \\
\hline Other, $n(\%)$ & 0 & 0 & $2(7)$ \\
\hline Educational level—adults only & $N=83$ & $N=41$ & $N=15$ \\
\hline Grade school, $n(\%)$ & $1(1)$ & 0 & 0 \\
\hline Technical degree, $n(\%)$ & $2(2)$ & $1(2)$ & $1(7)$ \\
\hline High school diploma, $n(\%)$ & $4(5)$ & $7(17)$ & $3(20)$ \\
\hline Some college, $n(\%)$ & $4(5)$ & $10(24)$ & $4(27)$ \\
\hline College degree, $n(\%)$ & $33(40)$ & $17(41)$ & $2(13)$ \\
\hline Graduate/professional school, $n(\%)$ & $37(45)$ & $6(15)$ & $3(20)$ \\
\hline Other, $n(\%)$ & $2(2)$ & 0 & $2(13)$ \\
\hline On ERT_-adults & $72(87 \%, n=83)$ & $28(68 \%, n=41)$ & N/A \\
\hline$<1$ year, $n(\%)$ & $4(5)$ & $5(12)$ & N/A \\
\hline $1-5$ years, $n(\%)$ & $20(24)$ & $21(51)$ & N/A \\
\hline $6-10$ years, $n(\%)$ & $16(19)$ & $2(5)$ & N/A \\
\hline$>10$ years, $n(\%)$ & $32(39)$ & N/A & N/A \\
\hline On ERT - children & $5(42 \%, n=12)$ & $2(50 \%, n=4)$ & N/A \\
\hline$<1$ year, $n(\%)$ & 0 & 0 & N/A \\
\hline $1-5$ years, $n(\%)$ & $1(8)$ & $2(50)$ & N/A \\
\hline $6-10$ years, $n(\%)$ & $4(33)$ & 0 & N/A \\
\hline$>10$ years, $n(\%)$ & 0 & N/A & N/A \\
\hline \multicolumn{4}{|l|}{ Use of CAMs } \\
\hline Adults, $n(\%)$ & $37(45)$ & $17(41)$ & $7(47)$ \\
\hline Children, $n(\%)$ & $1(8)$ & $2(50)$ & $4(33)$ \\
\hline
\end{tabular}


Table 2 Most common supplements used by adult patients With LSD

\begin{tabular}{|c|c|c|c|c|c|c|}
\hline Supplement & $\begin{array}{l}\text { Type } 1 \text { Gaucher, } \\
n(\%)(n=83)\end{array}$ & $\begin{array}{c}\text { Perceived } \\
\text { effectiveness }^{a}\end{array}$ & $\begin{array}{c}\text { Fabry, } \\
n(\%) \\
(n=41)\end{array}$ & $\begin{array}{c}\text { Perceived } \\
\text { effectiveness }^{a}\end{array}$ & $\begin{array}{c}\text { Type B Niemann-Pick, } \\
n(\%)(n=15)\end{array}$ & $\begin{array}{c}\text { Perceived } \\
\text { effectiveness }^{a}\end{array}$ \\
\hline Any supplement & $28(34)$ & & $12(29)$ & & $8(53)$ & \\
\hline Glucosamine & $6(7)$ & $1.7(n=3)$ & 0 & N/A & $2(13)$ & $0.0(n=1)$ \\
\hline Chondroitin & $1(1)$ & $0(n=1)$ & 0 & N/A & 0 & N/A \\
\hline Glucosamine + chondriotin & $11(13)$ & $1.9(n=7)$ & $2(5)$ & $\mathrm{N} / \mathrm{A}$ & $1(7)$ & $2.0(n=1)$ \\
\hline Antioxidants & $12(14)$ & $0.5(n=2)$ & $5(12)$ & $1.0(n=1)$ & $2(12)$ & $3.5(n=2)$ \\
\hline Omega-3 $\mathrm{FA}^{b}$ & $10(12)$ & $3.3(n=3)$ & $5(12)$ & $0.0(n=1)$ & $6(40)$ & $1.5(n=2)$ \\
\hline Echinacea & $8(10)$ & $1(n=1)$ & $3(7)$ & $4.5(n=2)$ & $2(13)$ & $3.5(n=2)$ \\
\hline Flaxseed & $5(6)$ & N/A & $5(12)$ & $5.0(n=1)$ & $2(13)$ & N/A \\
\hline MSM & $8(10)$ & $3.0(n=3)$ & 0 & N/A & $1(7)$ & N/A \\
\hline Gingko & $3(4)$ & $1.0(n=1)$ & $4(10)$ & $2.0(n=2)$ & $1(7)$ & N/A \\
\hline Megavitamins & $2(2)$ & $0(n=1)$ & $4(10)$ & $3.0(n=4)$ & $1(7)$ & $3.0(n=1)$ \\
\hline Ginseng & $5(6)$ & N/A & $3(7)$ & $5.0(n=1)$ & $3(20)$ & $5.0(n=1)$ \\
\hline Ginger & $3(4)$ & $1.0(n=1)$ & $3(7)$ & $3.0(n=1)$ & $1(7)$ & N/A \\
\hline
\end{tabular}

Table 3 Most common supplements, treatments, and alternative providers used by children ${ }^{a}$

\begin{tabular}{|c|c|c|c|c|c|c|}
\hline & \multicolumn{2}{|c|}{ Type 1 Gaucher $(n=12)$} & \multicolumn{2}{|c|}{ Fabry $(n=4)$} & \multicolumn{2}{|c|}{ Type B Niemann-Pick $(n=12)$} \\
\hline \multicolumn{7}{|l|}{ Supplement } \\
\hline Flaxseed & \multicolumn{2}{|c|}{0} & \multicolumn{2}{|c|}{0} & \multicolumn{2}{|c|}{$1(8 \%)$} \\
\hline Treatment & No. patients (\%) & $\begin{array}{c}\text { Perceived } \\
\text { effectiveness }\end{array}$ & No. patients (\%) & $\begin{array}{l}\text { Perceived } \\
\text { effectiveness }\end{array}$ & No. patients $(\%)$ & $\begin{array}{l}\text { Perceived } \\
\text { effectiveness }\end{array}$ \\
\hline Homeopathy & 0 & - & 0 & - & $2(17)$ & $4.0(n=2)$ \\
\hline Relaxation therapy & 0 & - & $1(25)$ & - & $1(8)$ & $3.0(n=1)$ \\
\hline Spiritual/energy healing & 0 & - & $1(25)$ & $5.0(n=1)$ & $1(8)$ & - \\
\hline Massage & 0 & - & 0 & - & $1(8)$ & $3.0(n=1)$ \\
\hline Acupuncture & 0 & - & 0 & - & $1(8)$ & - \\
\hline Acupressure & 0 & - & 0 & - & $1(8)$ & $3.0(n=1)$ \\
\hline \multicolumn{7}{|l|}{ Provider } \\
\hline Homeopathy & 0 & - & 0 & - & $1(8)$ & - \\
\hline Naturopathy & 0 & - & 0 & - & $1(8)$ & - \\
\hline Other & 0 & - & 0 & - & $1(8)$ & - \\
\hline
\end{tabular}

${ }^{a}$ Perceived effectiveness for children $(<18$ years) was only reported for those on various CAM treatments in each disease group.

acroparesthesias, cardiac and gastrointestinal manifestations in Fabry disease. Among patients with type B Niemann-Pick disease, $47 \%$ of adult respondents used CAMs for their symptoms. CAM use did not correlate significantly with self-reported symptoms of fatigue or pain, which are common reasons for patients with other chronic disorders to seek out CAM approaches. ${ }^{2,16}$ In contrast, CAM use was more prevalent among patients with type 1
Gaucher, Fabry, and type B Niemann-Pick diseases who also used one or more conventional medical therapies and among those who had undergone an invasive procedure related to their disease. The latter finding is consistent with other reports, which indicate that CAM use increases as health status declines. ${ }^{2}$

The specific CAM approach used varied among patients with type 1 Gaucher, Fabry, and type B Niemann-Pick diseases. 
Table 4 Most common treatments used by adult patients with LSD

\begin{tabular}{|c|c|c|c|c|c|c|}
\hline Treatment & $\begin{array}{l}\text { Type } 1 \text { Gaucher, } \\
n(\%)(n=83)\end{array}$ & $\begin{array}{c}\text { Perceived } \\
\text { effectiveness }\end{array}$ & $\begin{array}{c}\text { Fabry, } \\
n(\%)(n=41)\end{array}$ & $\begin{array}{c}\text { Perceived } \\
\text { effectiveness }^{a}\end{array}$ & $\begin{array}{c}\text { Type B Niemann-Pick, } \\
n(\%)(n=15)\end{array}$ & $\begin{array}{c}\text { Perceived } \\
\text { effectiveness }{ }^{a}\end{array}$ \\
\hline Any treatment & $28(34)$ & - & $16(39)$ & - & $5(33)$ & - \\
\hline Massage & $10(12)$ & $3.0(n=8)$ & $5(12)$ & $3.5(n=2)$ & $4(27)$ & $4.0(n=4)$ \\
\hline Chiropractic & $8(10)$ & $3.2(n=6)$ & $3(7)$ & $3.5(n=2)$ & $3(20)$ & $3.5(n=2)$ \\
\hline Meditation & $6(7)$ & $4.4(n=5)$ & $5(12)$ & $2.8(n=4)$ & $3(20)$ & $4.0(n=3)$ \\
\hline Acupuncture & $9(11)$ & $2.8(n=8)$ & $1(2)$ & $4.0(n=1)$ & $2(13)$ & $2.5(n=2)$ \\
\hline Yoga & $5(6)$ & $2.3(n=3)$ & $1(2)$ & $3.0(n=1)$ & $3(20)$ & $4.5(n=4)$ \\
\hline Water therapy & $5(6)$ & $3.5(n=4)$ & $2(5)$ & $4.0(n=2)$ & $1(7)$ & - \\
\hline Acupressure & $5(6)$ & $5.0(n=1)$ & $1(2)$ & - & $1(7)$ & - \\
\hline Relaxation therapy & $3(4)$ & - & $3(7)$ & $2.7(n=6)$ & $1(7)$ & - \\
\hline Aromatherapy & $3(4)$ & - & $3(7)$ & - & - & $5.0(n=1)$ \\
\hline Magnetic therapy & $5(6)$ & $3.0(n=1)$ & $1(2)$ & - & 0 & - \\
\hline Homeopathy & $3(4)$ & - & $1(2)$ & - & $1(7)$ & - \\
\hline Chinese herbal medicine & $3(4)$ & - & $1(2)$ & - & $2(13)$ & - \\
\hline Spiritual/energy healing & $2(2)$ & $4.0(n=1)$ & $1(2)$ & - & $2(13)$ & - \\
\hline Biofeedback & $2(2)$ & $3.0(n=1)$ & $2(5)$ & - & 0 & - \\
\hline
\end{tabular}

Patients with type 1 Gaucher disease, who have bone involvement as a prominent feature, most frequently reported the use of glucosamine and/or chondroitin (18/83, 22\%), whereas patients with Fabry disease, who have significant vascular involvement, were more likely to use antioxidants and omega-3 fatty acids $(10 / 41,24 \%)$. In type B Niemann-Pick disease, omega-3 fatty acid was the most commonly used supplement, presumably for cardioprotection secondary to dyslipidemia. ${ }^{10}$ Considering that $55 \%$ of patients using CAM therapies were self-prescribing, it is likely that the abundant information available through health stores and on the internet was guiding the decisions of these patients in selecting what supplements to use.

Overall, only few supplements were rated by respondents as effective, and the perceived effectiveness was variable across the disease groups. The majority of patients continued to use various CAMs for several years, even though they rated their effectiveness as low or not effective. Of note, a commonly used supplement, glucosamine/chondroitin combined, was poorly rated for effectiveness with mean Likert scores of 1.9. In contrast, CAM therapies such as meditation and water therapy were more highly rated with mean Likert scores of 3.8 and 3.7, respectively. These ratings suggest that additional, controlled studies should be performed to determine whether these modalities are of any benefit and to further understand the role of other approaches, such as meditation, in improving patient wellbeing.

It is important to consider the potential adverse effects of CAMs in this patient population and the role of the treating physician in discussing these approaches with patients with LSDs. Specifically, there are safety concerns and potential adverse effects that can accompany CAM use. For example, among the CAM users in each group, $10 \%$ of those with type 1 Gaucher, $7 \%$ of Fabry, and 20\% of type B Niemann-Pick diseases used chiropractic treatment. This could be potentially harmful in patients with type 1 Gaucher or type B NiemannPick diseases who may have osteopenia or osteoporosis of the spine, which would be a relative contraindication to spinal manipulation. ${ }^{17,18}$ Similarly, there are adverse effects of many CAM supplements that should be considered before their use. For example, fish oils and omega-3 fatty acids in large doses can decrease platelet aggregation and prolong bleeding time, ${ }^{19}$ which may be harmful in type 1 Gaucher disease or type B Niemann-Pick disease, and to other patients with LSD who already have an underlying bleeding diathesis because of their disease or who may be on anticoagulants or other platelet inhibitors (e.g., patients with type 1 Gaucher or Fabry disease). Finally, Chinese herbal medicine preparations have been associated with organ toxicity including hepatorenal failure, ${ }^{10,11}$ which could potentially exacerbate preexisting liver dysfunction or renal involvement in patients with various LSDs including type 1 Gaucher, Fabry, and type B Niemann-Pick diseases.

In summary, this study documents that CAMs are used by patients with type 1 Gaucher, Fabry, and type B Niemann-Pick diseases and that most patients self-prescribe these therapies. Thus, physicians managing these and other patients with LSD should specifically inquire about CAM use and discuss the potential for adverse effects. Similarly, treating physicians should consider the use of certain CAM approaches in assisting their patients in achieving a better quality of life.

\section{ACKNOWLEDGMENTS}

Supported by Grant number K24 RR021991 from the National Center for Research Resources of the National Institutes of Health (to M.M.M.) and by a Grant (5 MO1 RR00071) for the Mount Sinai General Clinical Research Center from the National Center for Research Resources, National Institutes of 
Health. M.B. is the recipient of the NORD/Roscoe Brady Lysosomal Storage Disease Fellowship award.

The authors thank Dr. Jimmy Ko for his assistance with development of the survey.

\section{REFERENCES}

1. Barnes PM, Powell-Griner E, McFann K, Nahin RL. Complementary and alternative medicine use among adults: United States, 2002. Adv Data 2004;343:1-19.

2. Astin JA. Why patients use alternative medicine. JAMA 1998;279:15481553.

3. Eisenberg DM, Davis RB, Ettner SL, et al. Trends in alternative medicine use in the United States, 1990-1997: results of a follow-up national survey. JAMA 1998;280:1569-1575.

4. Nadir A, Reddy D, Van Thiel DH. Cascara sagrada-induced intrahepatic cholestasis causing portal hypertension: case report and review of herbal hepatotoxicity. Am J Gastroenterol 2000;95:3634-3637.

5. Borum ML. Fulminant exacerbation of autoimmune hepatitis after the use of ma huang. Am J Gastroenterol 2001;96:1654-1655.

6. Isnard Bagnis C, Deray G, Baumelou A, Le Quintrec M, Vanherweghem JL. Herbs and the kidney. Am J Kidney Dis 2004;44:1-11.

7. Jha V, Rathi M. Natural medicines causing acute kidney injury. Semin Nephro 2008;28:416-428.

8. Charrow J, Andersson HC, Kaplan P, et al. The Gaucher registry: demographics and disease characteristics of 1698 patients with Gaucher disease. Arch Intern Med 2000;160:2835-2843.

9. Grabowski GA, Beutler E. Gaucher disease. In: Scriver C, Beaudet A, Sly
W, Valle D, editors. The metabolic and molecular bases of inherited diseases. New York: McGraw-Hill, 2001:3635-3668.

10. Schuchman EH, Desnick RJ. Niemann-Pick disease types A and B: acid sphingomyelinase deficiencies. In: Scriver C, Beaudet A, Sly W, Valle D, editors. The metabolic and molecular bases of inherited diseases. New York: McGraw-Hill, 2001;3589-3610.

11. Desnick RJ, Ioannou YA, Eng CM. a-Galactosidase a deficiency: fabry disease. In: Scriver C, Beaudet A, Sly W, Valle D, editors. The metabolic and molecular bases of inherited diseases. New York: McGraw-Hill, 2001; 3733-3774.

12. Desnick RJ. Enzyme replacement and enhancement therapies for lysosomal diseases. J Inherit Metab Dis 2004;27:385-410.

13. Ernst E, Cassileth BR. The prevalence of complementary/alternative medicine in cancer: a systematic review. Cancer 1998;83:777-782.

14. Herman CJ, Allen P, Hunt WC, Prasad A, Brady TJ. Use of complementary therapies among primary care clinic patients with arthritis. Prev Chronic Dis 2004; 1 :A12

15. Quandt SA, Chen H, Grzywacz JG, Bell RA, Lang W, Arcury TA. Use of complementary and alternative medicine by persons with arthritis: results of the National Health Interview Survey. Arthritis Rheu 2005;53:748-755.

16. Artus M, Croft P, Lewis M. The use of CAM and conventional treatments among primary care consulters with chronic musculoskeletal pain. BMC Fam Pract 2007;8:26.

17. Shvartzman P, Abelson A. Complications of chiropractic treatment for back pain. Postgrad Med 1988;83:57-58, 61

18. Haldeman S, Rubinstein SM. Compression fractures in patients undergoing spinal manipulative therapy. J Manipulative Physiol Ther 1992;15:450-454.

19. Bays HE. Safety considerations with omega-3 fatty acid therapy. Am J Cardiol 2007;99:35C-43C. 